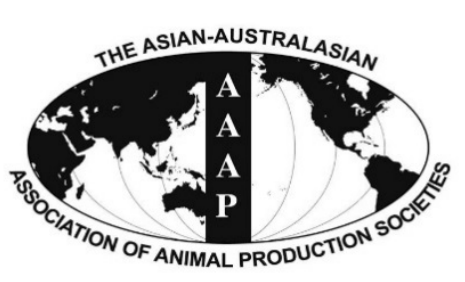

Open Access

Asian Australas. J. Anim. Sci.

Vol. 29, No. 3 : 327-332 March 2016

http://dx.doi.org/10.5713/ajas.15.0270

www.ajas.info

pISSN 1011-2367 elSSN 1976-5517

\title{
Microsatellite Analysis of the Genetic Diversity and Population Structure in Dairy Goats in Thailand
}

\author{
Somkiat Seilsuth ${ }^{1,2}$, Joo Hee Seo ${ }^{2}$, Hong Sik Kong ${ }^{2, *}$, and Gwang Joo Jeon ${ }^{2, *}$ \\ ${ }^{1}$ Faculty of Agriculture and Life Science, Chadrakasem Rajabhat University, Bangkok 10902, Thailand
}

\begin{abstract}
The genetic relationships between different populations and breeds of exotic dairy goats in Thailand were studied using 12 microsatellite markers. Blood samples were obtained from 211 goats from Department of Livestock Development breeding and research farms: 29 Anglonubian (AN), 21 Alpine (AP), 23 Jamunapari (JAM), 50 Saanen (SN), and 88 Toggenburg (TG). Five of the 12 microsatellite markers were found to be polymorphic. A mean of 7.40 alleles per locus was found, with a range from 5 (SPS115 and ETH225) to 11 (TGLA122). We found 24, 27, 19, 32, and 24 alleles in the AN, AP, JAM, SN, and TG breeds, respectively; 37 alleles were present in all breeds. The mean number of alleles in each population ranged from 3.2 (ETH225 locus) to 7.6 (TGLA122 locus). Genetic variability within the breeds was moderate as evidenced by the mean expected heterozygosity of 0.539 . The average observed heterozygosity across the 5 markers in all breeds was 0.529 with the maximum observed at the BM1818 locus (0.772) and the minimum at the ETH225 locus (0.248). The observed and expected heterozygosity for all breeds for the 5 microsatellite markers ranged from 0.419 to 0.772 and 0.227 to 0.792 , respectively. On the basis of their means, the TGLA122 and BM1818 loci were the most suitable markers for distinguishing genetic diversity among the goats. The estimated average $F_{i s}$ value for the breeds ranged from -0.044 (ETH225) to 0.180 (SPS115), while the estimated average $F_{s t}$ value ranged from 0.021 (SPS115) to 0.104 (ETH10). These results indicated that TGLA122 and BM1818 markers are suitable to be used for aiding conservation and breeding improvement strategies of dairy. (Key Words: Microsatellite, Genetic Diversity, Dairy Goat)
\end{abstract}

\section{INTRODUCTION}

Goats are the most widely spread domestic species across the world and play an important economic role in developing countries (Adriana et al., 2010). They are the smallest domesticated ruminants, have been domesticated for a long period, and are used for a variety of purposes; goats contribute substantially to rural economies as they can adapt to harsh environments. Goat and sheep milk is usually marketed as a mixture with cow or buffalo milk (Khan, 2008). Agronomically, the goat sector is well-established in developed countries such as Greece, Spain, France, Italy,

\footnotetext{
* Corresponding Authors: Hong Sik Kong. Tel: +82-31-670-5334, Fax: +82-504-42-4615, E-mail: kebinkhs@hknu.ac.kr / Gwang Joo Jeon. Tel: +82-31-670-5331, Fax: +82-504-42-4615, E-mail: gjjeon@hknu.ac.kr

${ }^{2}$ Genetic Informatics Center, Hankyong National University, Anseong 456-749, Korea.

Submitted Mar. 27, 2015; Revised Apr. 16, 2015; Accepted May 25, 2015
}

and Australia for the production of cheeses or baby food products. Dairy goats also help to support millions of people in malnourished populations in the developing world. Moreover, goat milk consumption is used as a therapeutic food by diabetic patients (Nagura, 2004), and by those with peptic ulcers, allergy and various gastrointestinal disorders that develop from intolerance to cow milk (Haenlein, 2004). Thailand has imported Saanen goats as an exotic dairy breed since 1948. In 2013, the total population of goats in the country was 440,277 , which were owned by 41,674 farmers; only $4.53 \%$ of the total goat population $(19,923$ head of 1,719 farmers) was dairy goats. The distribution of the goat population is related to the geographic rather than climate conditions, and they are particularly associated with the southernmost region and outskirts of Bangkok, areas where Thai Muslims live. The main exotic goat breeds in Thailand are Anglonubian (AN), Alpine (AP), Jamunapari (JAM), Saanen (SN), and Toggenburg (TG) and these are used by DLD in their breeding improvement plan. 
Genetic characterization of goat breeds requires a basic understanding of the variation both within and between populations. Microsatellites are useful in conservation genetics because of the high degree of polymorphism, which makes them extremely informative and provides very high discriminating power (Glaubitz and Moran, 2000). These properties of microsatellites allow a thorough assessment of the genetic variation and structure within and among populations (Bruford et al., 1996). Genetic diversity is essential for the long-term survival of species and populations, because it provides the raw material for adaptation and evolution, especially when environmental conditions change. The genetic diversity of many goat breeds has been investigated using microsatellite markers: Korean goat, Chinese goat and Saanen using 5 bovine, 2 ovine, and 2 caprine microsatellite markers (Kim et al., 2002); nine breeds of Chinese cashmere goat using 14 and 11 microsatellites (Li et al., 2008; Di et al., 2011); 18 East Asian indigenous goat populations using 26 microsatellite markers (Nomura et al., 2012); 20 Indian goat breeds using 25 microsatellite markers (Dixit et al., 2012); 5 Southern Indian goat breeds using 25 microsatellite markers (Dixit et al., 2010); Jamunapari goats using 23 microsatellite markers (Gour et al., 2006); the Barbari goat using 21 microsatellite markers (Ramamoorthi et al., 2009); 6 Tibetan and other goat breeds using 10 microsatellite markers (Wang et al., 2011); Mongolian goats using 10 microsatellite markers (Takahashi et al., 2008); 11 indigenous South-East Asian goat breeds using 25 microsatellite markers (Barker et al., 2001); Saanen, Alpine and native Brazilian goat breeds using 11 microsatellite markers (Adriana et al., 2006). In order to improve milk production by the indigenous goat population in Thailand, the government initiated a breeding strategy. This study was undertaken to determine the genetic variability and estimate genetic distances among 5 exotic dairy goat breeds in Thailand, namely Saanen, Alpine, Toggenburg, Jamunapari, and Anglonubian.

\section{MATERIALS AND METHODS}

\section{Sample collection, DNA extraction and quantification}

Blood samples were collected from 211 randomly selected and unrelated animals of 5 exotic dairy goat breeds in Thailand. These samples included 29 AN, 21 AP, 23 JAM, $50 \mathrm{SN}$, and $88 \mathrm{TG}$ goats. The animals were from herds on three breeding and research farms of the Department of Livestock Development, namely, Tae-Pa farm (Songkhla Province), Pangchong farm (Nakhon Rachasima Province), and Yala farm (Yala Province) and from farmers' flocks in Bangkok, Pra Nakhon Si Ayutthaya, Suphanburi, Pathumthane, and Ratchaburi Provinces. The blood samples were taken from the jugular vein using vacutainer tubes with K2-EDTA (ethylenediaminetetraacetic acid) anticoagulant. They were then kept in an ice-box before transport to the laboratory where they were stored at $-70^{\circ} \mathrm{C}$ until used for DNA extractions.

Genomic DNAs were prepared from blood samples according to the modified method described in the Kurabo handbook (ver. 3.1). In brief, cells were lysed by adding $200 \mu \mathrm{L}$ of the blood sample to a $1.5-\mathrm{mL}$ microtube containing $30-\mu \mathrm{L}$ EDB (Proteinase K.) and $250-\mu \mathrm{L}$ lysis buffer; the mixture was vortexed at maximum speed for 15 s, centrifuged for 1 to $3 \mathrm{~min}$ at 13,000 rpm, and incubated at $56^{\circ} \mathrm{C}$ for $20 \mathrm{~min}$. The mixture was vortexed again for $15 \mathrm{~s}$, re-incubated at $56^{\circ} \mathrm{C}$ for $10 \mathrm{~min}$, vortexed at a maximum speed for $15 \mathrm{~s}$, and $250 \mu \mathrm{L} 99 \%$ ethanol added. The extraction steps were run on a QG-810 machine (Kurabo, Osaka, Japan). The lysate was added to $26-\mathrm{mL}$ wash buffer and 9-mL elution buffer, then placed into a cartridge and the machine set to the DNA WHOLE BLOOD mode. After extraction, the genomic DNA was transferred to a microtube and quantitated by ND-1000 spectrophotometer (Thermo SCIENTIFIC, USA).

\section{Microsatellite polymorphism detection}

Studies have been undertaken to develop polymorphic DNA markers specific to this species. However, comparative genome studies have shown that microsatellite (MS) primer sequences are often conserved across related species and can be used for the development of markers in related species (Table 4). Therefore, we used 12 MS markers widely used in cattle (recommended by [International Society for Animal Genetics). Polymerase chain reaction (PCR) amplification and genotyping were performed at the Bioinformatic Center laboratory, Hankyong National University, Anseong, Korea. All 211 DNA samples were amplified using a GeneAmp PCR system 9700 (Applied Biosystems, Waltham, MA, USA). All the microsatellite markers were forwardly labeled with a capillary based dye, FAM (blue), VIC (green), or NED (yellow), to enable genotyping. The amplifications were carried out using $15 \mu \mathrm{L}$ reaction mixtures containing $2-\mu \mathrm{L}$ genomic DNA $(20-100 \mathrm{ng} / \mu \mathrm{L}), 2 \mu \mathrm{L}$ template genomic DNA (20 to $100 \mathrm{ng} / \mu \mathrm{L}, 0.5 \mu \mathrm{L}$ of each primer, $0.6-\mu \mathrm{L}$ hot start Taq DNA polymerase (Genetbio, Daejeon, Korea), 1.8 $\mu \mathrm{L}$ of $10 \times$ buffer, and $1.5 \mu \mathrm{L}$ of deoxynucleotide triphosphate (dNTPs). The PCR amplification conditions were: pre-denaturation step, $15 \mathrm{~min}$ at $95^{\circ} \mathrm{C}, 60 \mathrm{~s}$ at $94^{\circ} \mathrm{C}$, $75 \mathrm{~s}$ at $55^{\circ} \mathrm{C}$, and $60 \mathrm{~s}$ at $72^{\circ} \mathrm{C}$ for 5 cycles; $60 \mathrm{~s}$ at $94^{\circ} \mathrm{C}, 75$ $\mathrm{s}$ at $54^{\circ} \mathrm{C}$ and $60 \mathrm{~s}$ at $72^{\circ} \mathrm{C}$ for 10 cycles; $60 \mathrm{~s}$ at $94^{\circ} \mathrm{C}, 75 \mathrm{~s}$ at $55^{\circ} \mathrm{C}$ and $60 \mathrm{~s}$ at $72^{\circ} \mathrm{C}$ for 25 cycles. The final extension step was at $65^{\circ} \mathrm{C}$ for $30 \mathrm{~min}$ and then cooled to $8^{\circ} \mathrm{C}$. The amplification products were initially electrophoresed on a $2 \%$ agarose gel treated with ethidium bromide for later visualization of DNA bands under ultraviolet light. 
Table 1. Number of alleles of each polymorphic microsatellite in the different goat breeds

\begin{tabular}{lccccc}
\hline Population & TGLA122 & BM1818 & ETH10 & ETH225 & SPS115 \\
\hline AN & 7 & 8 & 3 & 2 & 4 \\
AP & 9 & 7 & 4 & 4 & 3 \\
JAM & 4 & 6 & 3 & 3 & 3 \\
SN & 11 & 7 & 4 & 5 & 5 \\
TG & 7 & 8 & 4 & 2 & 3 \\
Total (mean) & 7.6 & 7.2 & 3.6 & 3.2 & 3.6 \\
\hline
\end{tabular}

AN, Anglonubian; AP, Alpine; JAM, Jamunapari; SN, Saanen; TG, Toggenburg.

\section{Microsatellite marker genotyping}

The amplified DNA was genotyped using an automated Genetic Analyzer 3130xl (Applied Biosystems, USA). The genotyping reaction contained $1 \mu \mathrm{L}$ of PCR products, 8.9 $\mu \mathrm{L}$ of Hi-Di formamide and $0.1 \mu \mathrm{L}$ of GeneScan-500LIZ size standard in $10-\mu \mathrm{L}$ total volume. The genotyping results were obtained using GeneMapper V 4.1 (Applied Biosystems, USA).

\section{Statistical analysis}

The genotyped data was analyzed using Cervus V 3.0 program (Marshall et al., 1998) and Excel MS toolkit version 3.1 (Park, 2001) to calculate allele frequencies at each locus for each population, average number of allele per population and heterozygosity value (expected and observed). The amount of inbreeding-like effects within subpopulations $\left(F_{s t}\right)$, among subpopulations $\left(F_{i s}\right)$ and within the entire population $\left(F_{i t}\right)$ was analyzed by F-statistics (Wright, 1965). The Dispan program (Ota, 1993) was used to calculate $\mathrm{D}_{\mathrm{A}}$ genetic distances between populations. The neighbor joining method (Saitou and Nei, 1987) was used to construct a phylogenetic tree. Principal components analysis (PCA) was calculated for the 5 MS markers using GenAlEx 6.4 program.

\section{RESULTS AND DISCUSSION}

\section{Genetic diversity and differentiation}

Only 5 (TGLA122, BM1818, ETH10, ETH225, and SPS115) of the 12 microsatellite markers were polymorphic. In total, 37 alleles were identified at these 5 loci in the 211
Table 2. $\mathrm{H}_{\exp }$ and $\mathrm{H}_{\mathrm{obs}}$, PIC for 5 microsatellite markers in the 5 goat breeds

\begin{tabular}{lcccc}
\hline Population & No. of samples & $\mathrm{H}_{\exp }$ & $\mathrm{H}_{\text {obs }}$ & PIC \\
\hline AN & 29 & 0.703 & 0.559 & 0.486 \\
AP & 21 & 0.792 & 0.526 & 0.525 \\
JAM & 23 & 0.501 & 0.546 & 0.449 \\
SN & 50 & 0.180 & 0.530 & 0.531 \\
TG & 88 & 0.517 & 0.482 & 0.492 \\
Total & 211 & 0.539 & 0.529 & 0.497 \\
\hline
\end{tabular}

$\mathrm{H}_{\text {exp }}$, expected heterozygosity; $\mathrm{H}_{\mathrm{obs}}$, observed heterozygosity; PIC, polymorphism information content; AN, Anglonubian; AP, Alpine; JAM, Jamunapari; SN, Saanen; TG, Toggenburg.

individuals. A mean of 7.40 alleles per locus was found, with a range from 5 (SPS115 and ETH225) to 11 (TGLA122). In the study, the 5 exotic dairy goat breeds showed the most diverse to be $\mathrm{SN}$, which had 32 alleles, while JAM showed the least diversity with a total of 19 alleles (Table 1).

The heterozygosity (expected heterozygosity $\left[\mathrm{H}_{\mathrm{exp}}\right]$ and observed heterozygosity $\left[\mathrm{H}_{\exp }\right]$ ) and polymorphic information content (PIC) value for the 5 dairy goat breeds in Thailand are summarized in Table 2. $\mathrm{H}_{\mathrm{exp}}, \mathrm{H}_{\mathrm{obs}}$, and PIC ranged from $0.180(\mathrm{SN})$ to $0.792(\mathrm{AP}), 0.482(\mathrm{TG})$ to 0.559 (AN), and 0.449 (JAM) to $0.531(\mathrm{SN})$, respectively. The mean values of $\mathrm{H}_{\mathrm{exp}}, \mathrm{H}_{\mathrm{obs}}$, and PIC for overall loci and breeds were $0.539,0.529$, and 0.497 , respectively.

PIC value across the 5 microsatellite markers ranged from 0.205 (ETH225) to 0.748 (BM1818). In general, the PIC values were indicative of the high polymorphic nature of the microsatellites analyzed. TGLA122 and BM1818 markers seem the most effective of those tested for analyzing polymorphism in the goat populations (Table 3). The observed heterozygosity per locus ranged from 0.248 (ETH225) to 0.772 (BM1818) with an average of 0.529. The high number of alleles at TGLA122 and BM1818 provided sufficient polymorphism for analysis and indicates the appropriateness of the selected loci for assessing genetic variation. In order to investigate genetic relationships and breed differentiation, highly polymorphic MS markers are selected (FAO, 2004; Seo et al., 2013). MS markers were previously used for estimation of genotypic diversity of heterozygosity and PIC value informativeness in animal

Table 3. $\mathrm{H}_{\mathrm{exp}}$ and $\mathrm{H}_{\mathrm{obs}}$, PIC and overall F-statistics for 5 microsatellite markers in the sampled population

\begin{tabular}{lccccccc}
\hline Marker & No. of alleles & $\mathrm{H}_{\exp }$ & $\mathrm{H}_{\text {obs }}$ & PIC & $F_{s t}(\theta)$ & $F_{i t}(F)$ & $F_{\text {is }}(f)$ \\
\hline TGLA122 & 11 & 0.701 & 0.674 & 0.657 & 0.095 & 0.116 & 0.024 \\
BM1818 & 10 & 0.792 & 0.772 & 0.748 & 0.058 & 0.105 & 0.049 \\
ETH10 & 6 & 0.522 & 0.530 & 0.453 & 0.104 & 0.106 & 0.002 \\
ETH225 & 5 & 0.227 & 0.248 & 0.205 & 0.034 & -0.008 & -0.044 \\
SPS115 & 5 & 0.497 & 0.419 & 0.422 & 0.021 & 0.197 & 0.180 \\
Mean & 7.40 & 0.548 & 0.529 & 0.497 & 0.069 & 0.115 & 0.050 \\
\hline
\end{tabular}

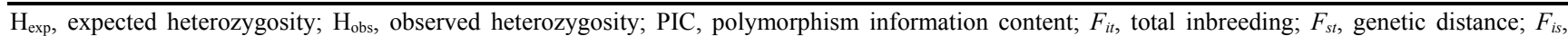
within inbreeding. 
breed selection (Berthouly et al., 2008). For the animal traceability, $\mathrm{PIC}>0.5$ and $\mathrm{H}_{\mathrm{exp}}>0.6$ are the most reasonable informative loci for application in genetics (Botstein et al., 1980). The genetic analysis of 5 exotic dairy goat breeds in Thailand with 5 microsatellite markers showed moderate gene diversity. Among 5 microsatellite markers, TGLA122 and BM1818 were the most appropriate for analyzing diversity in these goat breeds as they showed a high allele number, $\mathrm{H}_{\mathrm{exp}}$, and PIC.

According to Wright's (1965), $F$-statistics were observed in fixation index as genetic differentiation $\left(F_{s t}\right)$, the global heterozygote deficit among five goat breeds $\left(F_{i t}\right)$ and the heterozygote deficit within line $\left(F_{i s}\right)$ among the $5 \mathrm{MS}$ markers (Table 3). All of the loci, except ETH225, showed positive $F_{\text {is }}$ values, with an average value of 0.050 , indicating a deficiency of heterozygosity within the breeds. The cause of this deficiency might be inbreeding or the Wahlund effect. These high inbreeding values could be due to small population sizes, small numbers of breeding males or limited geographical dispersion. The average genetic differentiation between breeds $\left(F_{s t}\right)$ and total inbreeding $\left(F_{i t}\right)$ were 0.069 and 0.115 , respectively.

\section{Phylogenetic and structure analysis}

The phylogenetic tree showed (Figure 1) the closest genetic distance was between AP and TG breeds and the most distance between AP and SN breeds. From the history of the breeds, AP is known to have originated in France, TG and $\mathrm{SN}$ in Switzerland, AN is a mixed blood breed from United Kingdom, Middle East, and North America, and JAM originated in India. When we match the genetic distance information from the phylogenetic tree with information on the origin of each breed, the SN breed seemed to counter expectations; possibly, this is because most SN goats in Thailand were imported from Australia and New Zealand.

A PCA based on allele frequencies is presented. It is clear that TG, AP, and SN formed one group. AN and JAM were located in a different separated single quadrate that was distinct from these 3 other breeds (projection of breeds on axes 1 and 2). In the projection of breeds on axes 1 and 3, AN, AP, and TG might form one group while SN and JAM

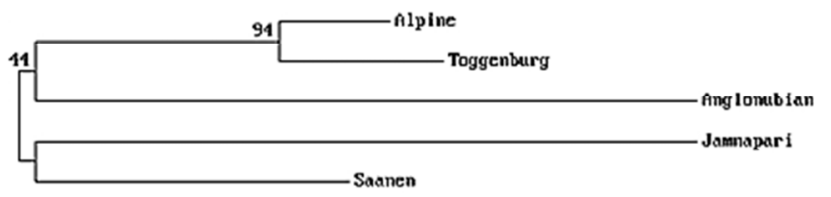

Figure 1. Phylogenetic tree showing the genetic divergence among the 5 goat breeds, using Nei's $\mathrm{D}_{\mathrm{A}}$ genetic distance on the basis of allele frequencies from 5 microsatellite markers. The numbers on the branches indicate percentage occurrence in 1,000 bootstrap replicates.

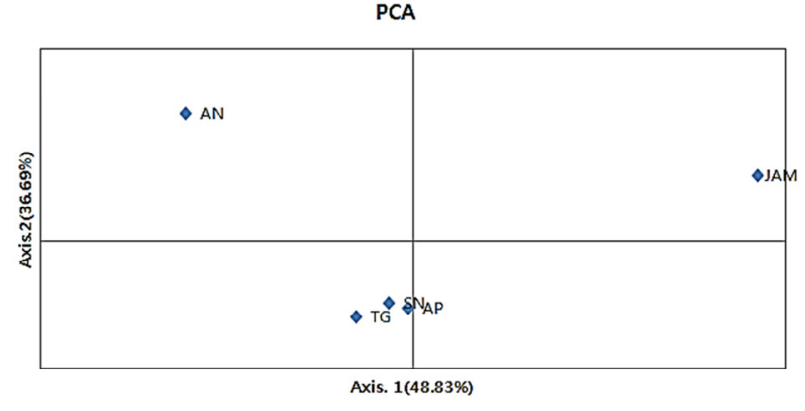

(A) Projection of breeds on axes 1 and 2

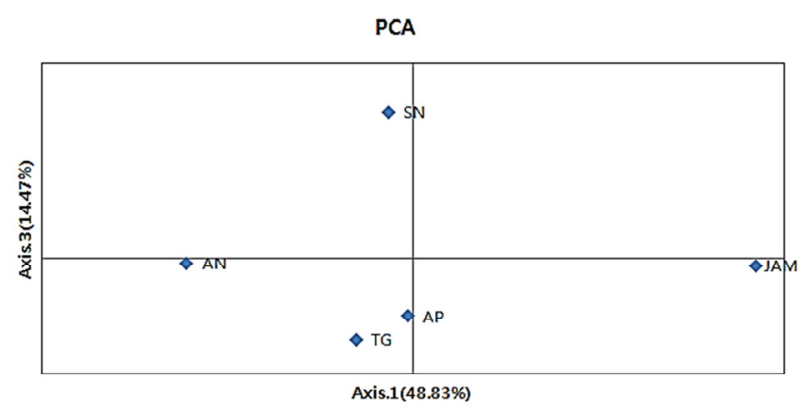

(B) Projection of breeds on axes 1 and 3

Figure 2. Principal components analysis (PCA) of allele frequencies of the 5 microsatellite markers typed in 5 dairy goat breeds using GenAlEx. (A) Projection of breeds on axes 1 and 2, (B) Projection of breeds on axes 1 and 3. AN, Anglonubian; AP, Alpine; JAM, Jamunapari; SN Saanen; TG, Toggenburg.

were in a single quadrate with each other (Figure 2).

\section{IMPLICATIONS}

The present study showed that the exotic dairy goat populations in Thailand have high genetic diversity with medium heterozygosity. The results of the present study will be useful in planning strategies for the future genetic improvement program of dairy goats in Thailand.

\section{CONFLICT OF INTEREST}

We certify that there is no conflict of interest with any financial organization regarding the material discussed in the manuscript.

\section{ACKNOWLEDGMENTS}

We wish to thank the staff of the Department of Livestock, Thailand, and Dr. Sansak Nakavisut and Dr. Suwit Anothaisinthawee of the Bureau of Animal Husbandry and Genetic Improvement for their support and information on Thai goat breeds. We are grateful to Mr. Tanongchai Chatchawan, head of the Taepa Farm, Mr. Chatchawan Wiriyasombat, head of the Yala farm, and all 
Table 4. Primer sequences of the 12 microsatellites used in this study

\begin{tabular}{|c|c|c|c|c|}
\hline Dye & MS & Ch. & Size range & Primer sequence \\
\hline \multirow[t]{12}{*}{ FAM } & TGAL227 & 18 & $76-104$ & F : CGAATTCCAAATCTGTTAATTTGCT \\
\hline & & & & R : ACAGACAGAAACTCAATGAAAGCA \\
\hline & BM2113 & 2 & $123-143$ & F : GCTGCCTTCTACCAAATACCC \\
\hline & & & & R : CTTCCTGAGAGAAGCAACACC \\
\hline & TGLA53 & 16 & $154-188$ & F : GCTTTCAGAAATAGTTTGCATTCA \\
\hline & & & & R : ATCTTCACATGATATTACAGCAGA \\
\hline & ETH10 & 5 & $212-224$ & F : GTTCAGGACTGGCCCTGCTAACA \\
\hline & & & & R : CCTCCAGCCCACTTTCTCTTCTC \\
\hline & SPS115 & 15 & $246-260$ & F : AAAGTGACACAACAGCTTCTCCAG \\
\hline & & & & R : AACGAGTGTCCTAGTTTGGCTGTG \\
\hline & BM1818 & 23 & $253-272$ & F : AGCTGGGAATATAACCAAAGG \\
\hline & & & & R : AGTGCTTTCAAGGTCCATGC \\
\hline \multirow[t]{6}{*}{ VIC } & TGLA126 & 20 & $116-122$ & F : CTAATTTAGAATGAGAGAGGCTTCT \\
\hline & & & & R : TTGGTCTCTATTCTCTGAATATTCC \\
\hline & TGLA122 & 21 & $137-181$ & F : CCCTCCTCCAGGTAAATCAGC \\
\hline & & & & R : AATCACATGGCAAATAAGTACATAC \\
\hline & INRA23 & 3 & $196-222$ & F : GAGTAGAGCTACAAGATAAACTTC \\
\hline & & & & R : TAACTACAGGGTGTTAGATGAACT \\
\hline \multirow[t]{6}{*}{ NED } & ETH3 & 19 & $105-125$ & F : GAACCTGCCTCTCCTGCATTGG \\
\hline & & & & R : ACTCTGCCTGTGGCCAAGTAGG \\
\hline & ETH225 & 9 & $141-159$ & F : GATCACCTTGCCACTATTTCCT \\
\hline & & & & R : ACATGACAGCCAGCTGCTACT \\
\hline & BM1824 & 1 & $178-192$ & F : GAGCAAGGTGTTTTTCCAATC \\
\hline & & & & R : CATTCTCCAACTGCTTCCTTG \\
\hline
\end{tabular}

Ch., chromosome number in cattle.

the staff of these farms, and to the dairy goat farmers in Central region for kindly helping during blood sample collection.

\section{REFERENCES}

Adriana, M. A., S. E. F. Guimaraes, C. S. Pereira, P. S. Lopes, M. T. Rodrigues, and T. M. M. Machado. 2010. Paternity in Brazilian goats with DNA microsatellites. R. Bras. Zootec. 39: 1011-1014.

Adriana, M. A., S. E. F. Guimaraes, T. M. M. Machado, P. S. Lopes, C. S. Pereira , F. L. R. Silva, M. T. Rodrigues, V. S. Columbiano, and C. G. Fonseca. 2006. Genetic diversity between herds of Alpine and Saanen dairy goats and the naturalized Brazilian Moxoto breed. Genet. Mol. Biol. 29:6774.

Barker, J. S. F., S. G. Tan, S. S. Moore, T. K. Mukherjee, J. L. Matheson, and O. S. Selvaraj. 2001. Genetic variation within and relationship among populations of Asian goats (Capra hircus). J. Anim. Breed. Genet. 118:213-233.

Berthouly, C., B. Bed'Hom, M. Tixier-Boichard, C. F. Chen, Y. P. Lee, D. Laloe, H. Legros, E. Verrier, and X. Rognon, 2008. Using molecular markers and multivariate methods to study the genetic diversity of local European and Asian chicken breeds. Anim. Genet. 39:121-129.

Botstein, D., R. L. White, M. Skolnik, and R. W. Davis. 1980. Construction of a genetic linkage map in man using restriction fragment length polymorphisms. Am. J. Hum. Genet. 32:314331.

Bruford, M. W., D. J. Cheesman, T. Coote, H. A. Green, S. A. Haines, C. O'Ryan, and T. R. Williams. 1996. Microsatellites and their application to conservation genetics. In: Molecular Genetic Approaches in Conservation (Eds. T. B. Smith and R. K. Wayne). Oxford University Press, New York. USA. pp. 278-297.

Di, R., S. M. Farhad Vahidi, Y. H. Ma, X. H. He, Q. J. Zhao, J. L. Han, W. J. Guan, M. X. Chu, W. Sun, and Y. P. Pu. 2011. Microsatellite analysis revealed genetic diversity and population structure among Chinese cashmere goats. Anim. Genet. 42:428-431.

Dixit, S. P., N. K. Verma, R. A. K. Aggarwal, M. K. Vyas, J. Rana, and A. Sharma. 2012. Genetic diversity and relationship among Indian goat breeds based on microsatellite markers. Small Rumin. Res. 105:38-45.

Dixit, S. P., N. K. Verma, R. A. K. Aggarwal, M. K. Vyas, J. Rana, A. Sharma, P. Tyagi, P. Arya, and B. R. Ulmek. 2010. Genetic diversity and relationship among southern Indian goat breeds base on microsatellite markers. Small Rumin. Res. 91:153-159.

FAO. 2004. Guidelines for development of national management of farm animal genetic resources plans. Measurement of Domestic Animal Genetic Diversity (MoDAD): Recommended microsatellite markers. Rome, Italy.

Glaubitz, J. C. and G. F. Moran. 2000. Genetic tools: The use of biochemical and molecular markers. In: Forest Conservation 
Genetics: Principles and Practice (Eds. A. G. Young, D. Boshier, and T. J. Boyle). CABI Publishing, Collingwood, Australia. pp. 39-59.

Gour, D. S., G. Malik, S. P. S, Ahlawat, A. K. Pandey, R. Sharma, N. Gupta, S. C. Gupta, P. S. Bisen, and D. Kumar. 2006. Analysis of genetic structure of Jamunapari goats by microsatellite markers. Small Rumin. Res. 66:140-149.

Haenlein, G. F. W. 2004. Goat milk in human nutrition. Small Rumin. Res. 51:155-163.

Khan, B. B. 2008. Health and Husbandry of Dairy Animals. TM Printers, Faisalabad, Pakistan.

Kim, K. S., J. S. Yeo, J. W. Lee, W. Kim, and C. B. Choi. 2002. Genetic diversity of goat from Korea and China using microsatellite analysis. Asian Australas. J. Anim. Sci. 15:461465.

Li, J. Y., H. Chen, X. Y. Lan, X. J. Kong, and L. J. Min. 2008. Genetic diversity of five Chinese goat breeds assessed by microsatellite markers. Czech J. Anim. Sci. 53:315-319.

Marshall, T. C., J. Slate, L. E. Kruuk, and J. M. Pemberton. 1998. Statistical confidence for likelihood-based paternity inference in natural populations. Mol. Ecol. 7:639-655.

Nagura, Y. 2004. Utilization of goat milk and meat in Japan. Farming, Japan. 36.

Nomura, K., K. Ishii, H. Dadi, Y. Takahashi, M. Minezawa, C. Y. Cho, Sutopo, M. O. Faruque, D. Nyamsamba, and T. Amano. 2012. Microsatellite DNA markers indicate three genetic lineages in East Asian indigenous goat populations. Anim. Genet. 43:760-767.
Ota, T. 1993. DISPAN: Genetic Distance and Phylogenetic Analysis. Pennsylvania State University Park, State College, PA, USA.

Park, S. D. E. 2001. The Excel microsatellite toolkit (version 3.1). Animal Genomics Laboratory, University College Dublin, Ireland.

Ramamoorthi, J., K. Thilagam, S. N. Sivaselvam, and S. M. Karthickeyan. 2009. Genetic characterization of Barbari goats using microsatellite markers. J. Vet. Sci. 10:73-76.

Saitou, N. and M. Nei. 1987. The neighbor-joining method: A new method for reconstructing phylogenetic trees. Mol. Biol. Evol. 4:406-425.

Seo, D. W., M. R. Hoque, N. R. Choi, H. Sultana, H. B. Park, K. N. Heo, B. S. Kang, H. T. Lim, S. H. Lee, C. Jo, and J. H. Lee. 2013. Discrimination of Korean native chicken lines using fifteen selected microsatellite markers. Asian Australas. J. Anim. Sci. 26:316-322.

Takahashi, H., D. Nyamsamba, B. Mandakh, Y. O. Zagdsuren, T. Amano, K. Nomura, M. Yokohama, S. Ito, and M. Minezawa. 2008. Genetic structure of Mongolian goat populations using microsatellite loci analysis. Asian Australas. J. Anim. Sci. 21:947-953.

Wang, Y., J. Wang, X. D. Zi, C. R. Huatai, X. Ouyang, and L. S. Liu. 2011. Genetic diversity of Tibetan goats of plateau type using microsatellite markers. Arch. Tierz. 54:188-197.

Wright, S. 1965. The interpretation of population structure by Fstatistics with special regard to systems of mating. Evolution 19:395-420. 